\title{
Impact of direct-acting antivirals on de novo occurrence of hepatocellular carcinoma in hepatitis C virus patients
}

\author{
Ming Yang ${ }^{1, \#, ~ R u i l a n ~ M a ~}{ }^{2, \#}$, Yuan Huang ${ }^{1}$, Lai Wei ${ }^{1}$ \\ ${ }^{1}$ Hepatopancreatobiliary Center, Beijing Tsinghua Changgung Hospital, Tsinghua University, Beijing 102218, China. \\ ${ }^{2}$ Department of radiotherapy, The Second Hospital of Dalian Medical University, Dalian, Liaoning 116027, China. \\ \#Authors contributed equally.
}

Correspondence to: Prof. Lai Wei, Hepatopancreatobiliary Center, Beijing Tsinghua Changgung Hospital, Tsinghua University, No.168 Litang Road, Changping District, Beijing 102218, China. E-mail: weelai@163.com

How to cite this article: Yang M, Ma R, Huang Y, Wei L. Impact of direct-acting antivirals on de novo occurrence of hepatocellular carcinoma in hepatitis C virus patients. Hepatoma Res 2020;6:31. http://dx.doi.org/10.20517/2394-5079.2019.45

Received: 10 Dec 2019 First Decision: 31 Mar 2020 Revised: 9 May 2020 Accepted: 13 May 2020 Published: 18 Jun 2020

Science Editor: Guang-Wen Cao Copy Editor: Jing-Wen Zhang Production Editor: Jing Yu

\begin{abstract}
Hepatitis C Virus (HCV) infection constitutes a significant burden to world health, leading to liver cirrhosis and hepatocellular carcinoma (HCC). In the past decades, pegylated interferon combined with ribavirin has been used extensively for HCV treatment, and interferon (IFN) is thought to have antitumor property. Direct-acting antivirals (DAAs) have fundamentally changed HCV therapy, due to their high efficacy and tolerability. However, recent studies have reported relatively high rates of HCC occurrence, and recurrence, following successful HCV treatment using DAAs. These studies were grossly underpowered due to their retrospective design, lack of untreated or IFN controls, small sample size, and limited patient follow-up time. From then, many retrospective and prospective cohort studies with larger size and longer follow-up duration after DAAs therapy have been published. These studies showed that treatment with DAAs can reduce the risk of HCC compared to no treatment, didn't increase the risk of HCC compared to IFN-based therapy after adjusting for the potential confounders of these two groups, and DAAs-induced sustained virological response decreased the risk of HCC compared to DAAs treatment failure. In conclusion, DAAs treatment doesn't appear to increase the development of HCC, even in cirrhotic patients. However, cirrhotic patients should be monitored for the development of HCC during and after DAAs treatment.
\end{abstract}

Keywords: Sustained virological response, hepatocellular carcinoma, liver cirrhosis

\footnotetext{
(ㄷ) $\left(\frac{1}{)}\right.$

(C) The Author(s) 2020. Open Access This article is licensed under a Creative Commons Attribution 4.0 International License (https://creativecommons.org/licenses/by/4.0/), which permits unrestricted use, sharing, adaptation, distribution and reproduction in any medium or format, for any purpose, even commercially, as long as you give appropriate credit to the original author(s) and the source, provide a link to the Creative Commons license, and indicate if changes were made.
}

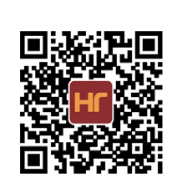




\section{INTRODUCTION}

It is estimated that 71 million people have chronic hepatitis $\mathrm{C}$ virus (HCV) infection, which can lead to liver cirrhosis and hepatocellular carcinoma $(\mathrm{HCC})^{[1]}$. It seems reasonable that HCV eradication would reduce the risk of HCV-related complications including HCC. Cirrhosis is the major risk factor of HCC and about $3 \%$ patients with HCV related cirrhosis develop HCC annually ${ }^{[2]}$. In the past decades, pegylated interferon combined with ribavirin (PR) has been widely used for the treatment of HCV. Despite the sustained virological response (SVR) rates associated with PR therapy not being high enough, and relatively more adverse events ${ }^{[3]}$ reported, studies have demonstrated that interferon (IFN)-induced SVR could reduce HCC incidence ${ }^{[4]}$. The annual incidence of HCC is mostly less than $2 \%$ in cirrhotic patients achieving SVR after IFN-based regimens ${ }^{[5,6]}$.

Direct-acting antivirals (DAAs) have fundamentally changed HCV therapy because of their high efficacy and tolerability, even in the patients with cirrhosis ${ }^{[7-9]}$. In these studies, patients with SVR showed improvements in disease severity and mortality. In 2016, relatively high rates of HCC occurrence and recurrence were reported after the success treatment of HCV using DAAs ${ }^{[10,11]}$. Since then, this has been a highly controversial topic.

This review article summarizes the relevant articles focusing on the impact of DAAs on de novo occurrence of HCC in HCV patients. We searched the MEDLINE electronic database using the search terms ["hepatitis C" (MeSH)], ("direct-acting antivirals"), and ["hepatocellular carcinoma" (MeSH)] from the start of the database (1996 year) until April 19, 2020. Searches were limited to human studies written in English. Eligible study designs included retrospective or prospective observational cohort studies, randomized controlled trials and interventional studies. Figure 1 shows the study flow chart.

\section{STUDIES SUPPORTING HIGH RATES OF HCC OCCURRENCE AFTER DAAS TREATMENT}

Table 1 summarizes the studies supporting high rates of HCC occurrence after DAAs treatment ${ }^{[1-14]}$. Conti et al.$^{[1]}$ from Italy reported that HCC was detected in $3.2 \%(9 / 285)$ cirrhotic patients at 24-week follow-up after DAAs therapy. Ravi et al. ${ }^{[14]}$ from the United States (US) reported that $9.1 \%$ (6/66 patients) of cirrhotic patients developed HCC within six months of DAAs treatment. Studies from Portugal ${ }^{[12]}$ and Austria ${ }^{[13]}$ also reported high rates of HCC occurrence after DAAs treatment. This data raised concerns that DAAs may promote the development of HCC. However, these studies were underpowered because of their retrospective design, lack of untreated or IFN controls, small sample size, and limited follow-up time.

\section{POSSIBLE MECHANISMS OF HCC OCCURRENCE AFTER DAAS TREATMENT}

There is a complex equilibrium between pro tumor factors such as HCV and inflammation and anti-tumor factors such as the immune system. A rapid reduction in the HCV viral load by DAAs treatment might impair immune surveillance, resulting in the development of HCC. Serti et al. ${ }^{[15]}$ reported DAAs treatment was associated with a rapid decreased activation of natural killer cells. Meissner et al. ${ }^{[16]}$ reported that HCV clearance by DAAs treatment was accompanied by down regulation of IFN-stimulated genes and the levels of type II and III IFNs. The serum level of microRNA-122, a regulator of HCV replication and tumor suppressor against $\mathrm{HCC}^{[17]}$, decreased in patients with IFN-free therapy induced SVR ${ }^{[18]}$. Debes et al. ${ }^{[19]}$ reported a panel of cytokines, apoptosis markers, and growth factors with higher levels before DAAs therapy in patients with new HCC compared with controls. Interestingly, their results suggested that the immune background rather than DAAs mediated immune modulation would lead to HCC development.

\section{STUDIES AGAINST HIGH RATES OF HCC DEVELOPMENT AFTER DAAS TREATMENT}

From 2016, many retrospective and prospective cohort studies with larger sizes and greater follow-up duration after DAAs therapy were published. Table 2 summarizes the studies not supporting high rates 


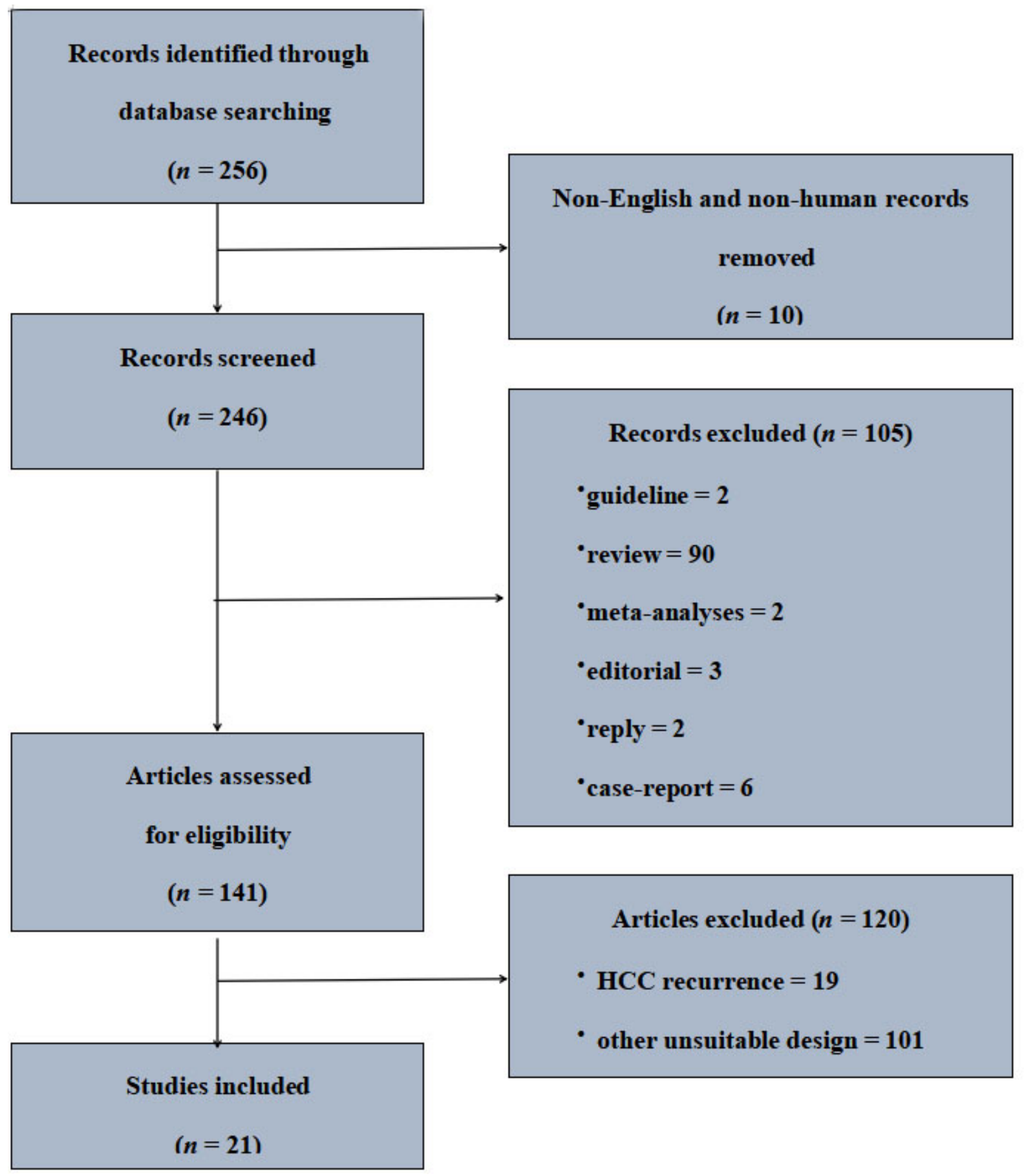

Figure 1. Study flow chart. HCC: hepatocellular carcinoma

Table 1. Studies in support of high rates of HCC odevelopment after DAAs treatment

\begin{tabular}{|c|c|c|c|c|c|c|}
\hline Ref. & Nature & Patients, $n$ & Liver disease stage & Median follow-up duration & $\mathrm{HCC}, n$ & Incidence of HCC \\
\hline Conti et al. ${ }^{[11]}$ & Retrospective & 285 & cirrhosis & 24 weeks & 9 & $3.16 \%$ in first 6 months \\
\hline Cardoso et al..$^{[12]}$ & Retrospective & 54 & cirrhosis & 1 year & 4 & $7.4 \%$ in the first year \\
\hline Kozbial et al. ${ }^{[13]}$ & Retrospective & 195 & all stages & 48 weeks & 13 & $6.60 \%$ in the first year \\
\hline Ravi et al.. ${ }^{[14]}$ & Retrospective & 66 & cirrhosis & 6 months & 6 & $9.1 \%$ in first 6 months \\
\hline
\end{tabular}

HCC: hepatocellular carcinoma; DAAs: direct-acting antivirals 


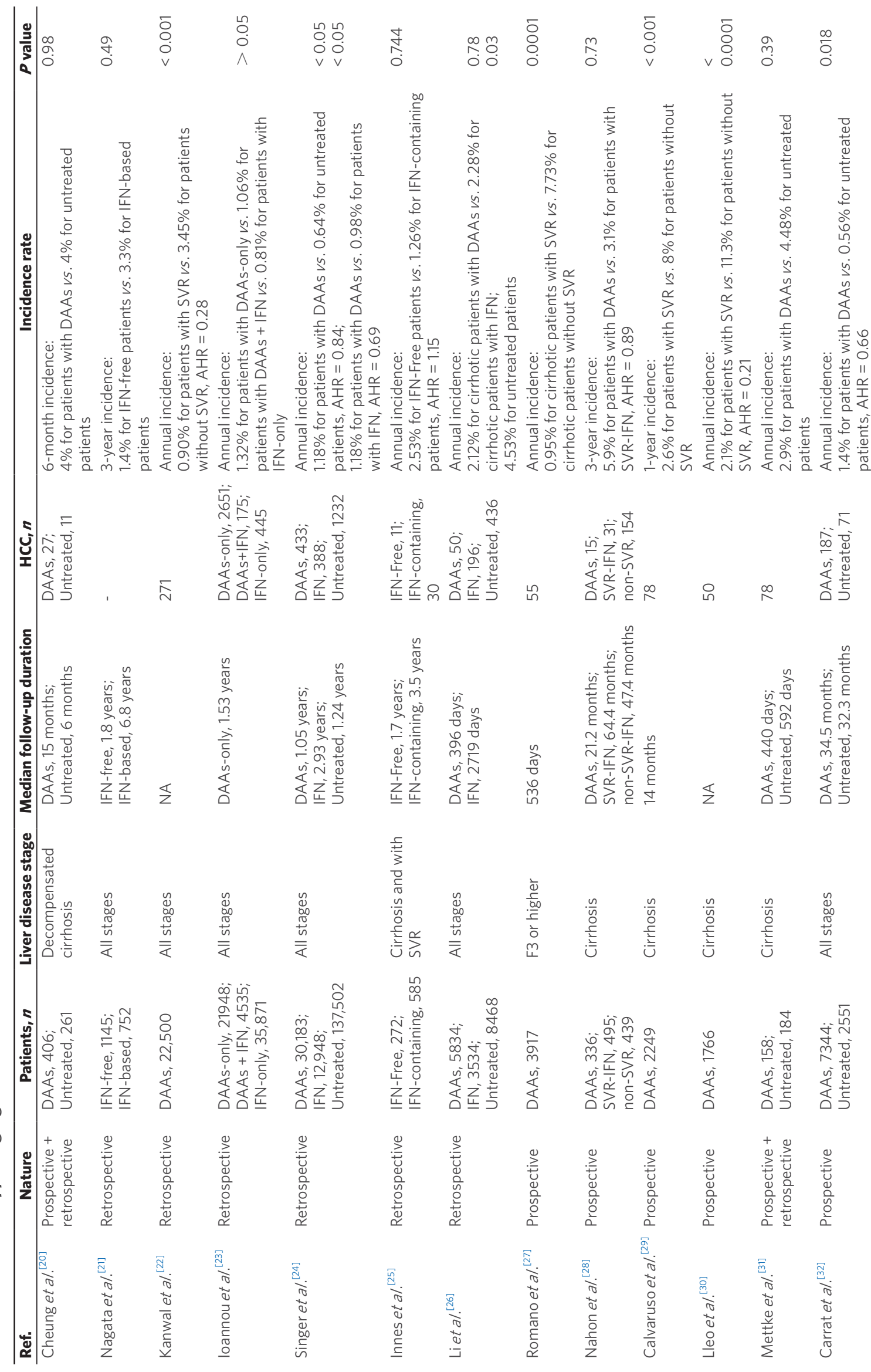




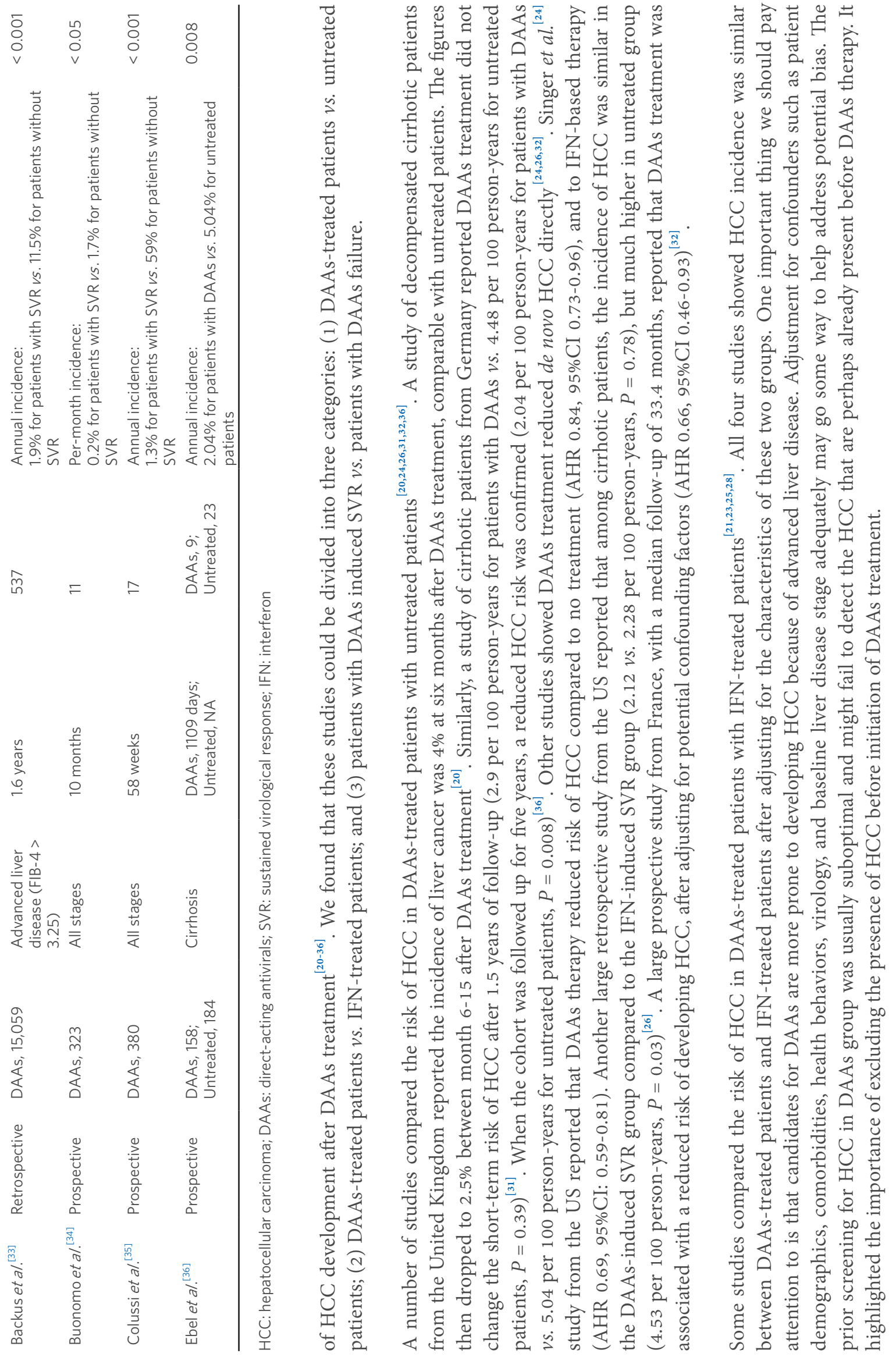


Other studies compared the risk of HCC in DAAs-cured patients with DAAs-failed patients ${ }^{[22,27,29,30,33-35]}$. All of these studies showed that DAAs-induced SVR decreased the incidence of HCC. The HCC risk reduction by DAAs treatment was evident not only in patients without cirrhosis, but also in patients with cirrhosis. Romano et al.$^{[27]}$ reported that the incidence of HCC was higher during the first year $(0.46 \%$ in F3, $1.49 \%$ in CTP-A and 3.61\% in CTP-B cirrhosis, respectively), and declined in the second year ( $0 \%$ in F3, $0.2 \%$ in CTP-A, and $0.69 \%$ in CTP-B cirrhosis, respectively). But some studies reported that in cirrhotic patients with DAAs-induced SVR, the incidence of HCC was usually still higher than $1.5 \%$ above which HCC surveillance is cost-effective. Kanwal et al ${ }^{[37]}$ reported the quarterly incidence rate of HCC remained stable between 1.5 to 2.3 per 100 person-years in patients with cirrhosis, which indicated HCC risk of cirrhotic patients cured with DAAs did not progress or regress during follow-up. Ide et al. ${ }^{[38]}$ found the one, two, and three-year cumulative incidences of HCC in patients with cirrhosis were $2.5 \%, 5.2 \%$, and $10.0 \%$ respectively. Recently, Ioannou et al. ${ }^{[39]}$ reported that in DAAs-treated patients with cirrhosis and a fibrosis index based on four factors (FIB-4) with scores $\geq 3.25$, the annual HCC incidence decreased from $3.8 \%$ in the first year after SVR to $2.4 \%$ by the fourth year, which was still at high risk of developing HCC. Although these studies with more than three years follow-up have confirmed HCC risk is not increased after SVR by DAAs ${ }^{[37-39]}$, the changes in HCC incidence over time deserve to be further clarified in longer-term studies.

Physicians are most interested in which patients should undergo HCC surveillance after achieving SVR by DAAs. Male gender, older age, alcohol abuse, diabetes mellitus, the existence of advanced fibrosis (F3) or cirrhosis, higher alpha-fetoprotein and no SVR are risk factors for HCC occurrence. The existence of cirrhosis is the most important risk factor for HCC development. Therefore, guidelines recommend patients with advanced liver fibrosis or cirrhosis at the time of DAAs treatment should stay in HCC surveillance even after DAA-induced SVR. FIB-4 and aspartate aminotransferase to platelet ratio index (APRI) are easily accessible non-invasive indicators which can be used as stratification risk factors for HCC development, alongside cirrhosis. Kanwal et al. ${ }^{[37]}$ divided cirrhotic patients who achieved SVR with DAAs into three groups: patients who had persistently high FIB-4/APRI over time, patients who experienced a decline in FIB-4/APRI, and patients who had persistently low FIB-4/APRI. Annual HCC incidence remained below $1.5 \%$ in the third subgroup, suggesting that it might be possible to exclude these cirrhotic patients from HCC surveillance programs. On the contrary, the annual HCC incidence was between $0.4 \%$ to $1.6 \%$ in non-cirrhotic patients but with high FIB-4/APRI subgroup (FIB-4>3.25/APRI $>1.5$ ), which was high enough to recommend HCC surveillance in these patients.

Although the impact of DAAs treatment and HCC has been extensively published, our review has some strengths. Firstly, we divide the studies not supporting high rates of HCC occurrence after DAAs treatment into three categories, which facilitates easy comparison between studies. Secondly, we include the most recent published evidence on this topic up to April, 2020, with the majority of studies published in 2019 and 2020, with follow-up of three to five years. Thirdly, we discuss the changes in HCC incidence over time following DAAs-induced HCV eradication. Fourthly, we emphasize FIB-4/APRI as the stratification factors besides cirrhosis, which is more useful for the patients with F3 fibrosis.

\section{CONCLUSION}

DAAs treatment doesn't appear to increase the occurrence of HCC, even in the cirrhotic patients. DAAs treatment should be considered in all HCV patients. Cirrhotic patients should be monitored for development of HCC during and after DAAs treatment.

\section{DECLARATIONS}

\section{Authors' contributions}

Made substantial contributions to conception and design of the study and performed data acquisition and interpretation: Yang M, Ma R

Made manuscript revision: Wei L, Huang Y 


\section{Availability of data and materials}

Not applicable.

\section{Financial support and sponsorship}

None.

\section{Conflicts of interest}

All authors declared that there are no conflicts of interest.

\section{Ethical approval and consent to participate}

Not applicable.

\section{Consent for publication}

Not applicable.

\section{Copyright}

(c) The Author(s) 2020.

\section{REFERENCES}

1. World Health Organization. Hepatitis C. Available from: https://www.who.int/news-room/fact-sheets/detail/hepatitis-c [Last accessed on 18 May 2020]

2. El-Serag HB. Hepatocellular carcinoma. N Engl J Med 2011;365:1118-27.

3. Fried MW, Shiffman ML, Reddy KR, Smith C, Marinos G, et al. Peginterferon alfa-2a plus ribavirin for chronic hepatitis C virus infection. N Engl J Med 2002;347:975-82.

4. Morgan RL, Baack B, Smith BD, Yartel A, Pitasi M, et al. Eradication of hepatitis C virus infection and the development of hepatocellular carcinoma: a meta-analysis of observational studies. Ann Intern Med 2013;158:329-37.

5. Bruno S, Stroffolini T, Colombo M, Bollani S, Benvegnù L, et al.; Italian Association of the Study of the Liver Disease (AISF). Sustained virological response to interferon-alpha is associated with improved outcome in HCV-related cirrhosis: a retrospective study. Hepatology 2007;45:579-87.

6. Cardoso AC, Moucari R, Figueiredo-Mendes C, Ripault MP, Giuily N, et al. Impact of peginterferon and ribavirin therapy on hepatocellular carcinoma: incidence and survival in hepatitis C patients with advanced fibrosis. J Hepatol 2010;52:652-7.

7. Curry MP, O’Leary JG, Bzowej N, Muir AJ, Korenblat KM, et al.; ASTRAL-4 Investigators. Sofosbuvir and velpatasvir for HCV in patients with decompensated cirrhosis. N Engl J Med 2015;373:2618-28.

8. Foster GR, Irving WL, Cheung MC, Walker AJ, Hudson BE, et al.; HCV Research, UK. Impact of direct acting antiviral therapy in patients with chronic hepatitis C and decompensated cirrhosis. J Hepatol 2016;64:1224-31.

9. Crespo G, Trota N, Londoño MC, Mauro E, Baliellas C, et al. The efficacy of direct anti-HCV drugs improves early post-liver transplant survival and induces significant changes in waiting list composition. J Hepatol 2018;69:11-7.

10. Reig M, Mariño Z, Perelló C, Iñarrairaegui M, Ribeiro A, et al. Unexpected high rate of early tumor recurrence in patients with HCVrelated HCC undergoing interferon-free therapy. J Hepatol 2016;65:719-26.

11. Conti F, Buonfiglioli F, Scuteri A, Crespi C, Bolondi L, et al. Early occurrence and recurrence of hepatocellular carcinoma in HCV-related cirrhosis treated with direct-acting antivirals. J Hepatol 2016;65:727-33.

12. Cardoso H, Vale AM, Rodrigues S, Gonçalves R, Albuquerque A, et al. High incidence of hepatocellular carcinoma following successful interferon-free antiviral therapy for hepatitis C associated cirrhosis. J Hepatol 2016;65:1070-1.

13. Kozbial K, Moser S, Schwarzer R, Laferl H, Al-Zoairy R, et al. Unexpected high incidence of hepatocellular carcinoma in cirrhotic patients with sustained virologic response following interferon-free direct-acting antiviral treatment. J Hepatol 2016;65:856-8.

14. Ravi S, Axley P, Jones D, Kodali S, Simpson H, et al. Unusually high rates of hepatocellular carcinoma after treatment with direct-acting antiviral therapy for hepatitis C related cirrhosis. Gastroenterology 2017;152:911-2.

15. Serti E, Chepa-Lotrea X, Kim YJ, Keane M, Fryzek N, et al. Successful interferon-free therapy of chronic hepatitis C virus infection normalizes natural killer cell function. Gastroenterology 2015;149:190-200.e2.

16. Meissner EG, Wu D, Osinusi A, Bon D, Virtaneva K, et al. Endogenous intrahepatic IFNs and association with IFN-free HCV treatment outcome. J Clin Invest 2014;124:3352-63.

17. Tsai WC, Hsu PW, Lai TC, Chau GY, Lin CW, et al. MicroRNA-122, a tumor suppressor microRNA that regulates intrahepatic metastasis of hepatocellular carcinoma. Hepatology 2009;49:1571-82.

18. Waring JF, Dumas EO, Abel S, Coakley E, Cohen DE, et al. Serum miR-122 may serve as a biomarker for response to direct acting antivirals: effect of paritaprevir/R with dasabuvir or ombitasvir on miR-122 in HCV-infected subjects. J Viral Hepat 2016;23:96-104.

19. Debes JD, van Tilborg M, Groothuismink ZMA, Hansen BE, Schulze Zur Wiesch J, et al. Levels of cytokines in serum associate 
with development of hepatocellular carcinoma in patients with HCV infection treated with direct-acting antivirals. Gastroenterology 2018;154:515-517.e3.

20. Cheung MCM, Walker AJ, Hudson BE, Verma S, McLauchlan J, et al.; HCV Research UK. Outcomes after successful direct-acting antiviral therapy for patients with chronic hepatitis C and decompensated cirrhosis. J Hepatol 2016;65:741-7.

21. Nagata H, Nakagawa M, Asahina Y, Sato A, Asano Y, et al.; Ochanomizu Liver Conference Study Group. Effect of interferon-based and -free therapy on early occurrence and recurrence of hepatocellular carcinoma in chronic hepatitis C. J Hepatol 2017;67:933-9.

22. Kanwal F, Kramer J, Asch SM, Chayanupatkul M, Cao Y, et al. Risk of hepatocellular cancer in HCV patients treated with direct-acting antiviral agents. Gastroenterology 2017;153:996-1005.e1.

23. Ioannou GN, Green PK, Berry K. HCV eradication induced by direct-acting antiviral agents reduces the risk of hepatocellular carcinoma. J Hepatol 2017:25-32.

24. Singer AW, Reddy KR, Telep LE, Osinusi AO, Brainard DM, et al. Direct-acting antiviral treatment for hepatitis C virus infection and risk of incident liver cancer: a retrospective cohort study. Aliment Pharmacol Ther 2018;47:1278-87.

25. Innes H, Barclay ST, Hayes PC, Fraser A, Dillon JF, et al. The risk of hepatocellular carcinoma in cirrhotic patients with hepatitis $\mathrm{C}$ and sustained viral response: role of the treatment regimen. J Hepatol 2018;68:646-54.

26. Li DK, Ren Y, Fierer DS, Rutledge S, Shaikh OS, et al. The short-term incidence of hepatocellular carcinoma is not increased after hepatitis C treatment with direct-acting antivirals: an ERCHIVES study. Hepatology 2018;67:2244-53.

27. Romano A, Angeli P, Piovesan S, Noventa F, Anastassopoulos G, et al. Newly diagnosed hepatocellular carcinoma in patients with advanced hepatitis C treated with DAAs: a prospective population study. J Hepatol 2018;69:345-52.

28. Nahon P, Layese R, Bourcier V, Cagnot C, Marcellin P, et al.; ANRS CO12 CirVir Group. Incidence of hepatocellular carcinoma after direct antiviral therapy for HCV in patients with cirrhosis included in surveillance programs. Gastroenterology 2018;155:1436-50.e6.

29. Calvaruso V, Cabibbo G, Cacciola I, Petta S, Madonia S, et al.; Rete Sicilia Selezione Terapia-HCV (RESIST-HCV). Incidence of hepatocellular carcinoma in patients with $\mathrm{HCV}$-associated cirrhosis treated with direct-acting antiviral agents. Gastroenterology 2018;155:411-21.e4.

30. Lleo A, Aglitti A, Aghemo A, Maisonneuve P, Bruno S, et al.; collaborators. Predictors of hepatocellular carcinoma in HCV cirrhotic patients treated with direct acting antivirals. Dig Liver Dis 2019;51:310-7.

31. Mettke F, Schlevogt B, Deterding K, Wranke A, Smith A, et al. Interferon-free therapy of chronic hepatitis C with direct-acting antivirals does not change the short-term risk for de novo hepatocellular carcinoma in patients with liver cirrhosis. Aliment Pharmacol Ther 2018;47:516-25.

32. Carrat F, Fontaine H, Dorival C, Simony M, Diallo A, et al. Clinical outcomes in patients with chronic hepatitis C after direct-acting antiviral treatment: a prospective cohort study. Lancet 2019;393:1453-64.

33. Backus LI, Belperio PS, Shahoumian TA, Mole LA. Impact of sustained virologic response with direct-acting antiviral treatment on mortality in patients with advanced liver disease. Hepatology 2019;69:487-97.

34. Buonomo AR, Scotto R, Coppola C, Pinchera B, Viceconte G, et al. Direct acting antivirals treatment for hepatitis C virus infection does not increase the incidence of de novo hepatocellular carcinoma occurrence: Results from an Italian real-life cohort (LINA cohort). Medicine (Baltimore) 2020;99:e18948.

35. Colussi G, Donnini D, Brizzi RF, Maier S, Valenti L, et al. Sustained virologic response to direct-acting antiviral agents predicts better outcomes in hepatitis C virus-infected patients: a retrospective study. World J Gastroenterol 2019;25:6094-106.

36. Ebel F, Deterding K, Port K, Schlevogt B, Manns MP, et al. Letter: a 5-year long-term follow-up study after DAA treatment confirms a reduced HCC risk in a central European cohort of HCV patients with liver cirrhosis. Aliment Pharmacol Ther 2020;51:194-5.

37. Kanwal F, Kramer JR, Asch SM, Cao Y, Li L, et al. Long-term risk of hepatocellular carcinoma in HCV patients treated with direct acting antiviral agents. Hepatology 2020;71:44-55.

38. Ide T, Koga H, Nakano M, Hashimoto S, Yatsuhashi H, et al. Direct-acting antiviral agents do not increase the incidence of hepatocellular carcinoma development: a prospective, multicenter study. Hepatol Int 2019;13:293-301.

39. Ioannou GN, Beste LA, Green PK, Singal AG, Tapper EB, et al. Increased risk for hepatocellular carcinoma persists up to 10 years after HCV eradication in patients with baseline cirrhosis or high FIB-4 scores. Gastroenterology 2019;157:1264-78.e4. 